\title{
The Coordination and Channel Conflicts in Supply Chain Based on Stackelberg game and Gain Sharing
}

\author{
Jinping Qi \\ Lanzhou Jiaotong University \\ Lanzhou, Gansu, China \\ a445645889@163.com
}

\begin{abstract}
This paper considers a dual channels supply chain including one manufacturer and one retailer. Manufacturer can use their own sales channels, but also the use the channels belong to retails. As the electronic channels are independent of retailer, this will cause the conflict between the channels. Therefore, we consider the manufacturers to cooperate in the electronic channel with the retailer and the electronic channels orders are delivered by retailer to complete. In the first part, we introduce the related content. And then, we establish the theoretical model can realize the dual channel supply chain coordination with revenue sharing based on Stackelberg game. At last, we discuss the effect of retailer's price when electronic channel is independent of the retailer and the revenue sharing ratio of electronic channels on cooperation, then find the optimal strategy of cooperation between manufacturer in electronic channels and retailer in some cases by numerical examples.
\end{abstract}

Keywords: Stackelberg game, Dual-channel Supply chain, profit sharing

\section{Introduction}

The rapid development of Internet and electronic commerce make the coexistence of two channel mode: the traditional sales channel and electronic direct channel become the main distribution channel of manufacturing enterprises. This phenomenon makes the communication distance between enterprises and consumers are greatly reduced. Many manufacturers preserve the traditional distribution channels and begin to exploit the electronic direct channel model at the same time .This combination of electronic direct channel and traditional channel on dual channel mode has become a major feature of the current manufacturing enterprises. And some large companies in the actual business operation has successfully implemented the electronic direct marketing channels, such as Lenovo, Sony, Samsung etc. However, because the dual-channel supply chain are more complex than the traditional supply chain in time and space, the double channel conflict among members of supply chain becomes more and more intense. Therefore, there is an important significance on the issue of coordination of dual channel supply chain for manufacturing enterprises to implement the dual channel effectively.

Conflict and coordination of channel has been one of the hottest issues in theoretical study and practical application of domestic and foreign enterprises. Chiang et al., study the influence of online direct sales on the retail pricing sales and profit on traditional channel [1]. Demrongsir et al., Study the effects of the service and distribution costs on dual channel. The results show that the direct channel exists to increase supply chain profits [2]. Arya, Mittendorf and Sappingtou Study the Pareto improvement to realize the manufacturer and the retailer profits under certain conditions on adding the direct online channel when 
manufacturers produce the goods have a cost advantage and retailer distribution the product cost advantage [3]. Liu and Zhang found the income of the manufacturer increase and the retailer's profit always decrease, but retailers still insist on getting into price discrimination strategy to prevent manufacturers direct sales channel when manufacturers add online in the information technology environment of direct sales channels and retailers implement price discrimination strategy to customer [4]. Parlar Study the horizontal competition of product on substitutability problem [5]. Anupindi, Bassok and Zemel consider the horizontal competition coordination problems on alternative products [6]. Tasy et al., research the coordination when the upstream is the suppliers and also is competitor in downstream [7]. Yao et al., thought manufacturers can solve the conflict between electronic direct marketing channel and traditional channel by setting the appropriate wholesale price [8]. But Kurata argue that the wholesale price can't make the consistent effects on dual channel supply chain, but dynamic pricing strategy appropriate can do that, and make the game all parties benefit when the competition of brand and channel contention existing at the same time[9]. Yan (2009) that exploit the electronic direct channel can help retailers to improve the service level and suggests that in a certain range, this way can coordinate the double channel [10]. Seifert established the mathematical model that retailers can demand for online supplement not satisfied, also sell excess orders online. And the analytical solution is derived to solve different circumstances of the optimal order quantity. The result proves that the electronic direct channel will enable retailers to obtain huge profits as the auxiliary channels of traditional distribution channels [11]. Cai (2009) point out that the price discount contract can effectively improve the dual channel supply chain performance through adjusting the traditional distribution channel prices and electronic direct channel price [12]. Yan and Huang studied the coordination of two kinds of dual channel supply chain in the service price sensitive demand condition [13]. Qu and Guo shared coordination contract of the dual channel supply chain through the improvement of income [14]. Xie and Huang (2007) implement the quantity discount model in dual channel supply chain coordination, and makes the two sides to achieve a win-win by adjusting the quantity discount rate [15].Chiang designed a shared mechanism that share the cost of holding inventory and direct channel gains. This mechanism makes the dual channel supply chain coordinate [16]. Boyaci thought that the dual channel supply chain will achieve the coordination $\square$ when retailers only earn additional sales [17]. Raju and Zhang researched quantity discount and two part tariff contract to coordinate the supply chain according to the dominant retailer in a supply chain [18]. Kuksov and Pazgal studied the slotting fee compensation strategy on a supply chain with a manufacturer and a retailer [19]. Geylani and Dukes researched the strategy face strong retailers [20]. Gupta and Loulou studied manufacturers sharing revenue of suppliers will also increase the profits of manufacturers and suppliers under certain conditions when the input cost innovative manufacturers share its suppliers [21]. Relevant Articles consider the traditional revenue sharing contract under the dual channel environment [22-25].

Therefore, how to play the advantages of dual channel is very important .At the same time, increasing profits, reducing inventory, and improving the service level and realizing the coordination and incentive of supply chain, is particularly critical .This paper consider a manufacturer to cooperate with retailer in the electronic channel in a dual channel supply chain, and the manufacturer deliver all the orders of electronic channel to retailer to complete. And the manufacturer share this part of the profits with retailer. Then, we compare the situation with the case of the electronic channel is independent of the retailer 


\section{Model Asumptions}

This paper considers a single product with the electronic channels and retail channels, supply chain system contains only 1 manufacturer and 1 retailer. Superscript "C" means the manufacturer control structure in the supply chain and Superscript "D" represents the supply chain for the decentralized control structure.

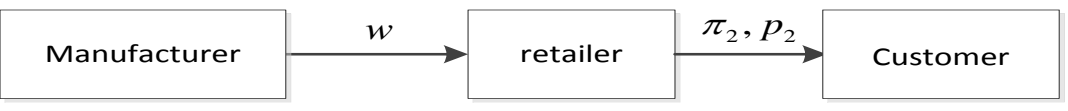

Figure 1. Traditional Channel

Symbols are as follows:

$\pi_{1}$ : the profit of manufacturer;

$\pi_{2}:$ the profit of retail;

$d_{1}$ : the demand of electronic channels;

$d_{2}::$ the demand of retail channels;

$p_{1}$ : the product price of electronic channels;

$p_{2}:$ the product price of retail channels;

$\omega$ :The wholesale price of manufacturer;

$c$ :Unit costs for manufacturers of products;

$r$ :the revenue sharing ratio of manufacturer to electronic channels, $r \in[0,1)$

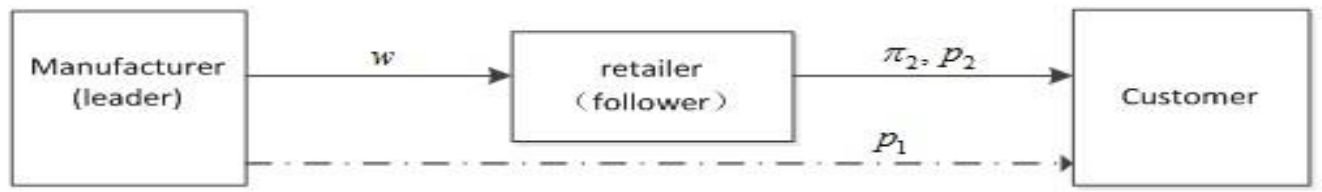

$\longrightarrow$ : traditional channel $\quad-\cdots \rightarrow$ : electronic channel

Figure 2. Dual Channel Supply Chain in the Environment of Electronic Market

\section{When Manufacturers Deliver the Orders of Electronic Channels to} Retailer

We establish the following dual channel demand function:

(1) Electronic channels demand function:

$$
d_{1}=\left(a_{1}-b p_{1}\right)+\theta\left(p_{2}-p_{1}\right)
$$

(2) Retail demand function:

$$
d_{2}=\left(a_{2}-b p_{2}\right)+\theta\left(p_{1}-p_{2}\right)
$$

$a_{i}$ represents the potential scale of channel $i(i=1$ represents the digital channel,$i=2$ represents the retail channel. $b$ represents the elasticity coefficient of market demand for the price , $\theta$ represents the transfer coefficient of the market demand for the price difference. 


\subsection{The Revenue Function of Manufacturers Delivering the Orders of Electronic Channels to Retailer}

The income of the manufacturer includes electronic channel gains and wholesale earnings, so the profit of manufacturers is:

$$
\pi_{1}\left(p_{1}, p_{2}\right)=r\left(p_{1}-c\right) d_{1}+(\omega-c) d_{2}
$$

The profit of retailer is

$$
\pi_{2}\left(p_{1}, p_{2}\right)=\left(p_{2}-c\right) d_{2}+(1-r)\left(p_{1}-c\right) d_{1}
$$

The total profit of two channels is:

$$
\pi\left(p_{1}, p_{2}\right)=\left(p_{1}-c\right) d_{1}+\left(p_{2}-c\right) d_{2}
$$

\subsection{Dual Channel Supply Chain is controlled by Manufacturer when Manufacturers Deliver the Orders of Electronic Channels to Retailer}

If retailer belongs to manufacturer, we can proceed to optimize the dual channel supply chain as a whole. Solve the following optimization problem:

$$
\underset{p_{1}, p_{2}}{\operatorname{Max}} \pi\left(p_{1}, p_{2}\right)=\left(p_{1}-c\right) d_{1}+\left(p_{2}-c\right) d_{2}
$$

$\pi\left(p_{1}, p_{2}\right)$ takes the derivative of $p_{1}, p_{2}$, make them to zero and solve them simultaneous. We can get:

Proposition 1: The Optimal Pricing Strategy and Profit are:

$$
\begin{gathered}
p_{1}^{M, c}=\frac{a_{1} b+a_{1} \theta+a_{2} \theta+2 \theta b c+c b^{2}}{2 b^{2}+4 b \theta} \\
p_{1}^{M, c}=\frac{a_{1} b+a_{1} \theta+a_{2} \theta+2 \theta b c+c b^{2}}{2 b^{2}+4 b \theta} \\
d_{1}^{M, C}=\frac{a_{1}-b c}{2} d_{2}^{M, c}=\frac{a_{2}-b c}{2}
\end{gathered}
$$

From $p_{1}^{M, c}-p_{2}^{M, c}=\frac{a_{1}-a_{2}}{2 b+4 \theta}$, we can get conclusion 1 :

Conclusion 1: When the retailer belongs to manufacturer, the difference of the price of two channels is inverse ratio to the potential market size and is inverse ratio to the elasticity coefficient of the market demand to price; taking the strategy of high price to potential larger channel, manufacturers can get the maximum benefits.

Conclusion 1 means: manufacturer must take into account the two channel potential market scale effect and take the strategy of low price to the potential of smaller channel when manufacturer pricing. When the elasticity price of the market demand to price is large, the price difference of two channels will be smaller. And the demand flow in different channels becomes smaller to maintain demand for channel stability.

\subsection{Decentralized Control of Manufacturers Delivering the Orders of Electronic Channels to Retailer}


In this mode, the manufacturer and the retailer belong to different individuals, the manufacturer is the leader. Manufacturer chooses the product price of electronic channels: $p_{1}$ and the wholesale price of manufacturer $\omega$ to make the profit $\pi_{1}$ max. And then retail chooses the product price of retail channels $p_{2}$ to make the profit $\pi_{2} \max$ according to $p_{1}$ and $\omega$.Meet:

$$
\begin{aligned}
& p_{2}^{s}\left(p_{1}, \omega\right)=\arg \underset{p_{2}}{\operatorname{ax}} \pi_{2}\left(p_{1}, p_{2}\right) \\
& \underset{p_{1}}{\operatorname{Max}} \pi_{1}\left(p_{1}, r, p_{2}^{s}\left(p_{1}, \omega\right)\right)=r\left(p_{1}-c\right) d_{1}+d_{2}(\omega-c)
\end{aligned}
$$

$\pi_{2}\left(p_{1}, p_{2}\right)$ take the derivative of $p_{2}$, make them to zero, solve $p_{2}^{s}\left(p_{1}, \omega\right)$ and substitute it into $\pi_{1}\left(p_{1}, r, p_{2}^{s}\left(p_{1}, \omega\right)\right)$.And then take the derivative of $p_{1}, \omega$, make them to zero we can get conclusion 2:

Proposition 2: The Best Strategy of Decentralized Control when Manufacturer Deliver the Orders of Electronic Channels to Retailer

$$
\begin{gathered}
p_{1}^{M, D}=\frac{a_{1} b+a_{1} \theta+a_{2} \theta+2 \theta b c+c b^{2}}{2 b(b+2 \theta)} \\
\omega^{M, D}=\frac{a_{2} b^{2}+2 a_{2} b \theta+4 c b^{2} \theta+4 \theta b c-r \theta c b^{2}}{2 b\left(b^{2}+3 b \theta+2 \theta^{2}\right)}+\frac{-2 r \theta^{2} c b+a_{1} b r \theta+a_{1} r \theta^{2}+a_{2} r \theta^{2}}{2 b\left(b^{2}+3 b \theta+2 \theta^{2}\right)} \\
d_{1}^{M, D}=\frac{2 a_{1} b+2 a_{1} \theta+a_{2} \theta-2 b^{2} c-3 \theta c b^{2}}{4(b+\theta)} \\
p^{M, D}=\frac{c b^{3}+3 a_{2} b^{2}+4 c b^{2} \theta+4 \theta^{2} b c+6 a_{2} b \theta+2 a_{1} b \theta}{4 b(b+\theta)(b+2 \theta)}+\frac{2 a_{2} \theta^{2}+2 a_{1} r \theta^{22}}{4 b(b+\theta)(b+2 \theta)} \\
d_{1}^{M, D}=\frac{A_{0} \theta^{2}+A_{1} \theta+A_{2}}{8 b\left(b^{2}+3 b \theta+2 \theta^{2}\right)} \\
M_{2}^{M, D}=\frac{\left(-B_{0}+r B_{0}\right) \theta^{2}-\left(B_{1}+r B_{2}\right) \theta-\left(B_{3}+r B_{4}\right)}{16 b\left(b^{2}+3 b \theta+2 \theta^{2}\right)} \\
M_{0}=8 r c^{2} b^{2}-8 r a_{2} c d-8 r c b a_{1}+2 r a_{1}^{2}+2 r a_{2}^{2}+4 r a_{2} a_{1} \\
M_{3}=-8 a_{2} b a_{1}-8 a_{1}^{2} b+12 c b^{2} a_{2}-2 b a_{2}^{2}+24 a b^{2} a_{1}-18 c^{2} b^{3} \\
M_{2}=(2+8 r) c^{2} b^{3}+4 r a_{2} b a_{1}-4 c b^{2} a_{2}-12 r c b^{2} a_{1}-4 r a_{2} c b^{2}+4 r a_{1}^{2}+2 b a_{2}^{2} \\
(2 c+1) c^{2} b^{4}-2 c b^{3} a_{2}+2 r b^{2} a_{1}^{2}-4 r c b^{3} a_{1} c-4 r a_{1} c b^{2}+b^{2} a_{2}^{2}
\end{gathered}
$$




$$
\begin{gathered}
M_{5}=16 c^{2} b^{3}+8 a_{1} b+8 a_{1} b a_{2}-24 c b^{2} a_{1}-8 a_{2} c b^{2} \\
M_{6}=-5 c^{2} b^{4}-a_{2}^{2} b^{2}-4 b^{2} a_{1}^{2}+8 b^{3} a_{1} c+2 c b^{3} a_{2}-16 c^{2} b^{3} \\
M_{7}=-8 c b^{3} a_{1}+4 a_{1}^{2} b^{2}+4 c^{2} b^{4}
\end{gathered}
$$

The main attraction of electronic channels to customers is the low price. This paper assumes that the electronic channel price is not higher than the price of retail channels

\section{Hypothesis 1:}

$$
P_{1}^{M, D} \leq p_{2}^{M, D}
$$

From above Proposition we can get:

Conclusion 2: The optimal pricing strategy of electronic channels is the same in both decentralized control and manufacturers control when manufacturers deliver the orders of electronic channels to retailer. Conclusion 2 explain that if the manufacturers collaborate with the retailer in electronic channels, the optimal pricing of electronic channels is not affected by whether the retailer belonging to the manufacturer,

Conclusion 3: The demand of electronic channels $d_{1}^{M, D}$ in the model of decentralized control in larger than the demand of manufacture control $d_{1}^{M, c}$, and the demand in retailer channel is $d_{2}^{M, D}=\frac{d_{2}^{M, C}}{2}$

The conclusion 3 illustrates that the function of electronic channel is to provide information and services more than others to coordinate retail sales when retailer belong to manufacture which deliver the orders of electronic channels to retailer. Therefore, the demand of electronic channels is less, and the retail channel demand is more. When retailer is independent of the manufacturer, competition between electronic channels and retail channels exists and the function of electronic channels enhancement. Thus the demand of electronic channel increases and the retail demand decreases.

\section{When the Orders of Electronic Channel are Independent of Retailer}

\subsection{Revenue Function}

Revenue function changes are as follows:

The profit of manufacturer is

$$
\pi_{1}\left(p_{1}, p_{2}\right)=\left(p_{1}-c\right) d_{1}+(\omega-c) d_{2}
$$

The profit of retailer is

$$
\pi_{2}\left(p_{1}, p_{2}\right)=\left(p_{2}-\omega\right) d_{2}
$$

The total profit of two channels is:

$$
\pi\left(p_{1}, p_{2}\right)=\left(p_{1}-c\right) d_{1}+\left(p_{2}-c\right) d_{2}
$$




\subsection{Decentralized Control of Electronic Channel being Independent of Retailer}

In the decentralized model, the decision variable of manufacturer is $p_{1}$. Similar discussion follow proposition 2, here is proposition 3:

\section{Proposition 3:}

In the traditional dual channel supply chain model, if the model is decentralized control structure, the optimal strategy is:

$$
\begin{aligned}
& p_{1}^{I, D}=\frac{2 a_{1} b+2 a_{1} \theta+2 \omega^{I, D}+a_{2} \theta+2 \omega^{I, D} \theta^{2}}{2\left(b^{2}+4 b \theta+\theta^{2}\right)}+\frac{2 c b^{2}+3 \theta c b}{2\left(b^{2}+4 b \theta+\theta^{2}\right)} \\
& p_{2}^{I, D}=\frac{I_{0}+I_{1}}{4\left(2 b^{2}+4 b \theta+\theta^{2}\right)(b+\theta)} \\
& \pi_{1}^{I, D}=\frac{I_{8}+\theta\left(I_{6}+I_{7}\right)+\theta\left(I_{4}+I_{5}\right)+\theta^{3} I_{3}}{8\left(2 b^{2}+4 b \theta+\theta^{2}\right)(b+\theta)} \\
& \pi_{2}^{I, D}=\frac{\left(I_{9}-I_{10}\right)^{2}}{16\left(2 b^{2}+4 b \theta+\theta^{2}\right)(b+\theta)} \\
& d_{1}^{I, D}=\frac{2 a_{1} b+2 a_{1} \theta+a_{2} \theta-2 c b^{2}-3 \theta c b}{4(b+\theta)} \\
& d_{2}^{I, D}=\frac{I_{11}+I_{12}}{4\left(4 b \theta+2 b^{2}+\theta^{2}\right)} \\
& I_{0}=4 a_{2} b^{2}+8 b a_{2} \theta+3 \theta^{2} a_{2}+2 \theta b a_{1}+2 \theta^{2} a_{1} \\
& I_{1}=4 \omega^{I, D} \theta^{3}+12 \theta^{2} \omega^{I, D}+2 b^{2} c \theta+3 \theta^{2} b c+4 \omega^{I, D} b^{3}+12 b^{2} \omega^{I, D} \theta \\
& I_{3}=-8 a_{2} c+8 \omega^{I, D} a_{2}+8 a_{1} \omega^{I, D}+16 \omega^{I, D} c b-8 c a_{1}-16\left(\omega^{I, D}\right)^{2} b \\
& I_{4}=4 a_{1}^{2}-30 a_{2} c b+9 c^{2} b^{2}-28 c b a_{1}+16 b a_{1} \omega^{I, D} \\
& I_{5}=-40\left(\omega^{I, D}\right)^{2} b^{2}+40 \omega^{I, D} c b^{2}+a_{2}^{2}+24 \omega^{I, D} b a_{2}+4 a_{1} a_{2} \\
& I_{6}=8 b a_{1}^{2}+12 c^{2} b^{3}-32\left(\omega^{I, D}\right)^{2} b^{3}-28 b^{2} a_{1} c-8 b^{2} a_{1} \omega^{I, D} \\
& I_{7}=24 \omega^{I, D} b^{2} a_{2}-28 a_{2} c b^{2}+32\left(\omega^{I, D}\right)^{2} b^{3} c+4 a_{2} b a_{1} \\
& I_{8}=8 \omega^{I, D} c b^{4}+8 a_{2} \omega^{I, D} b^{3}-8\left(\omega^{I, D}\right)^{2} b^{4}-8 b^{3} a_{1} c-8 b^{3} a_{2} c+4 b^{4} c^{2}+4 b^{2} a_{1}^{2} \\
& I_{9}=3 \theta^{2} a_{2}+3 \theta^{2} b c+2 \theta^{2} a_{1}+8 \theta b a_{2}+2 b^{2} c \theta+2 \theta b a_{1}+4 b^{2} a_{2} \\
& I_{10}=8 \theta^{2} b \omega^{I, D}+12 b^{2} \omega^{I, D} \theta+4 b^{3} \omega^{I, D}
\end{aligned}
$$




$$
\begin{gathered}
I_{11}=3 \theta^{2} a_{2}+3 \theta^{2} c b-8 \theta^{3} b \omega^{I, D}+2 \theta a_{1}+8 \theta b a_{2} \\
I_{12}=2 b^{2} c \theta-12 b^{2} \omega^{I, D} \theta+2 \theta b a_{1}+4 b^{2} a_{2}-4 b^{3} \omega^{I, D}
\end{gathered}
$$

\section{Hypothesis 2:}

$$
p_{1}^{I, D} \leq p_{2}^{I, D}
$$

From proposition 3 can get the following conclusion 4 :

\section{Conclusion 4: $d_{1}^{I, D}=d_{2}^{I, D}$}

Conclusion 4 shows, the demand of electronic channels is not affected by the strategy of whether the electronic channels and retailer collaborate. This means manufacturers can't deliver the orders of electronic channel to retailer for the objective of improving electronic channel sales. Although the attraction of the service promotion and the greatly strengthened of electronic channel in this way. In the dual channel supply chain, manufacturers and retailers select mode from the angle of profit maximization. If $a_{1}=a_{2}, b=2 \theta$, we can get Conclusion 5.

Conclusion 5: When $\omega^{l, D} \in\left[\left(t_{2}, t_{0}\right) \cup\left(t_{1},+\infty\right)\right] \cap\left(t_{2}, s\right)$, the manufacturer's profit of delivering the orders of electronic channel to retailer is more than that is independent of retailer .Namely, $\pi_{1}^{M, D} \leq \pi_{2}^{M, D}$.

Conclusion 6: When $\omega^{I, D} \in\left(s_{0}, s\right)$, the retailer's profit of manufacturer delivering the orders of electronic channel to retailer is more than that is independent of retailer.

Conclusion 7: When $0 \leq r<\frac{13}{81}, \omega^{I, D} \in\left(s_{0}, s\right) \cap\left(t_{2}, t_{0}\right)$ or $\frac{47}{64}<r<1, \omega^{I, D} \in\left(s_{0}, s\right) \cap\left(t_{1},+\infty\right)$, manufacturer and retailer both choose the model of manufacturer delivering the orders of electronic channel to retailer

\section{Optimization Model of Dual Channel Supply Chain}

For the general case, we can use optimization model to analysis whether manufacturer delivers the orders of electronic channel to retailer. We assume that the price $\omega^{I, D}$ is known when the orders of electronic channel is independent of retailer. Manufacturers can encourage the retailer to accept the orders of electronic channel with change of the electronic channel profit allocation proportion: $r$.

We can establish the optimization model as follows:

$$
\left\{\begin{array}{l}
\underset{r}{\operatorname{ax} \pi_{1}^{M, D}(r)} \\
\text { s.t. } \\
\pi_{1}^{M, D}(r) \geq \pi_{1}^{I, D}\left(\omega^{I, D}\right) \\
\pi_{2}^{M, D}(r) \geq \pi_{2}^{I, D}\left(\omega^{I, D}\right) \\
0 \leq r<1
\end{array}\right.
$$


Substitute the parameters of the model in dual channel supply chain into above model. If the optimal solution of $r^{*}$ and $\pi \pi_{1}^{M, D}\left(r^{*}\right)$ exist, then the optimal strategies of a manufacturer and a retailer is the manufacturer delivers the orders of electronic channel to retailer. And the electronic channel profit allocation proportion is $r^{*}$.

Table 1. Comparison of Different Model

\begin{tabular}{|c|c|c|c|c|}
\hline & \multicolumn{2}{|c|}{$\begin{array}{l}\text { When manufacturer deliver the orders of } \\
\text { electronic channels to retailer }\end{array}$} & \multicolumn{2}{|c|}{$\begin{array}{l}\text { When the orders of electronic channel are } \\
\text { independent of retailer }\end{array}$} \\
\hline & manufacturer & retailer & manufacturer & retailer \\
\hline $\begin{array}{l}\text { Demand } \\
\text { function }\end{array}$ & $\begin{array}{l}d_{1}=\left(a_{1}-b p_{1}\right) \\
+\theta\left(p_{2}-p_{1}\right)\end{array}$ & $\begin{array}{l}d_{2}=\left(a_{2}-b p_{2}\right) \\
+\theta\left(p_{1}-p_{2}\right)\end{array}$ & $\begin{array}{l}d_{1}=\left(a_{1}-b p_{1}\right) \\
+\theta\left(p_{2}-p_{1}\right)\end{array}$ & $\begin{array}{l}d_{2}=\left(a_{2}-b p_{2}\right) \\
+\theta\left(p_{1}-p_{2}\right)\end{array}$ \\
\hline profit & $\begin{array}{l}\pi_{1}\left(p_{1}, p_{2}\right)=r\left(p_{1}-c\right) d_{1} \\
+(\omega-c) d_{2}\end{array}$ & $\begin{array}{l}\pi_{2}\left(p_{1}, p_{2}\right)=\left(p_{2}-c\right) d_{2} \\
+(1-r)\left(p_{1}-c\right) d_{1}\end{array}$ & $\begin{array}{l}\pi_{1}\left(p_{1}, p_{2}\right)=\left(p_{1}-c\right) d_{1} \\
+(\omega-c) d_{2}\end{array}$ & $\pi_{2}\left(p_{1}, p_{2}\right)=\left(p_{2}-\omega\right) d_{2}$ \\
\hline $\begin{array}{l}\text { Total } \\
\text { profit of } \\
\text { the } \\
\text { channel }\end{array}$ & \multicolumn{2}{|c|}{$\pi\left(p_{1}, p_{2}\right)=\left(p_{1}-c\right) d_{1}+\left(p_{2}-c\right) d_{2}$} & \multicolumn{2}{|c|}{$\pi\left(p_{1}, p_{2}\right)=\left(p_{1}-c\right) d_{1}+\left(p_{2}-c\right) d_{2}$} \\
\hline $\begin{array}{l}\text { profit } \\
\text { allocation } \\
\text { proportion }\end{array}$ & \multicolumn{4}{|c|}{$r$} \\
\hline
\end{tabular}

\section{The Example Analysis}

In the dual channel supply chain the different, we set $a_{1}=200, a_{2}=500, b=9, c=7$. We first suppose that the manufacturer of electronic channel profit allocation proportion is $r=0.8 \cdot T_{1}$ is the ratio of the profit of manufacturer and retailer when manufacturer deliver the orders of electronic channels to retailer; $T_{2}$ is the ratio of the profit of manufacturer and retailer When the orders of electronic channel are independent of retailer. We analysis the impact of the change of $\theta$ (the transfer coefficient of market demand to price) on the profit for manufacturer and retailer.

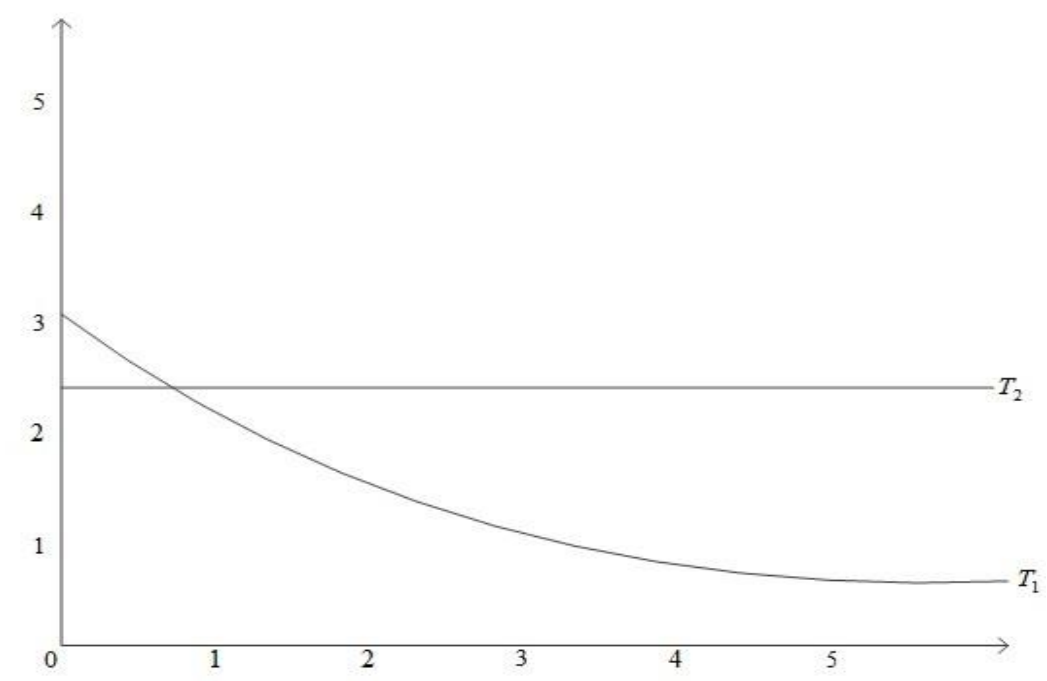

Figure 3. Comparison of the Profit of Manufacturer and the Retailer $(r=0.7)$ 


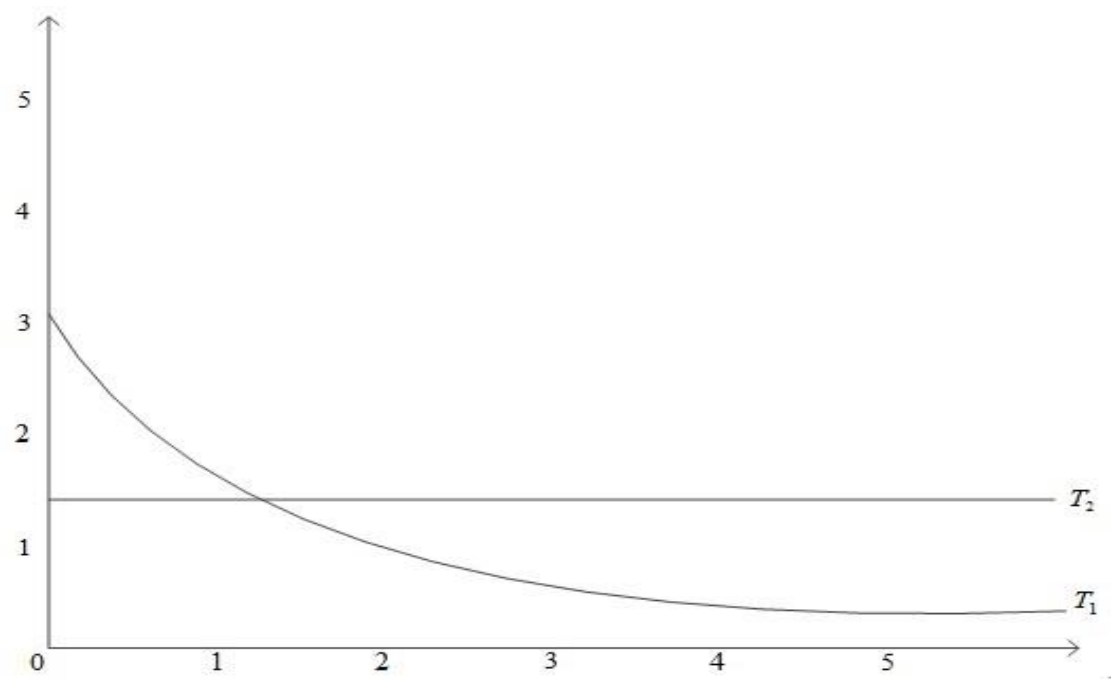

Figure 4. Comparison of the Profit of Manufacturer and the Retailer $(r=0.4)$

We can see in Figure 3 and Figure 4 that when the orders of electronic channel are independent of retailer, the profit of manufacturer and retailer do not change as the $\theta$ changes. When manufacturers deliver the orders of electronic channels to retailer, the profit of manufacturer and retailer decrease as the $\theta$ increase, i.e., the profit of manufacturer become less and the profit of retailer become more. This is because when delivery the orders of electronic channel are to retailer, the profit of electronic channel belongs to retailer. When $r$ become small, the slope of $T_{1}$ become large. The reason is that $r$ become smaller, the more profit retailer gets. But when the orders of electronic channel are independent of retailer, the ratio of the profit of both be more and more close.

Now, we see a the extreme example: $r=0$.

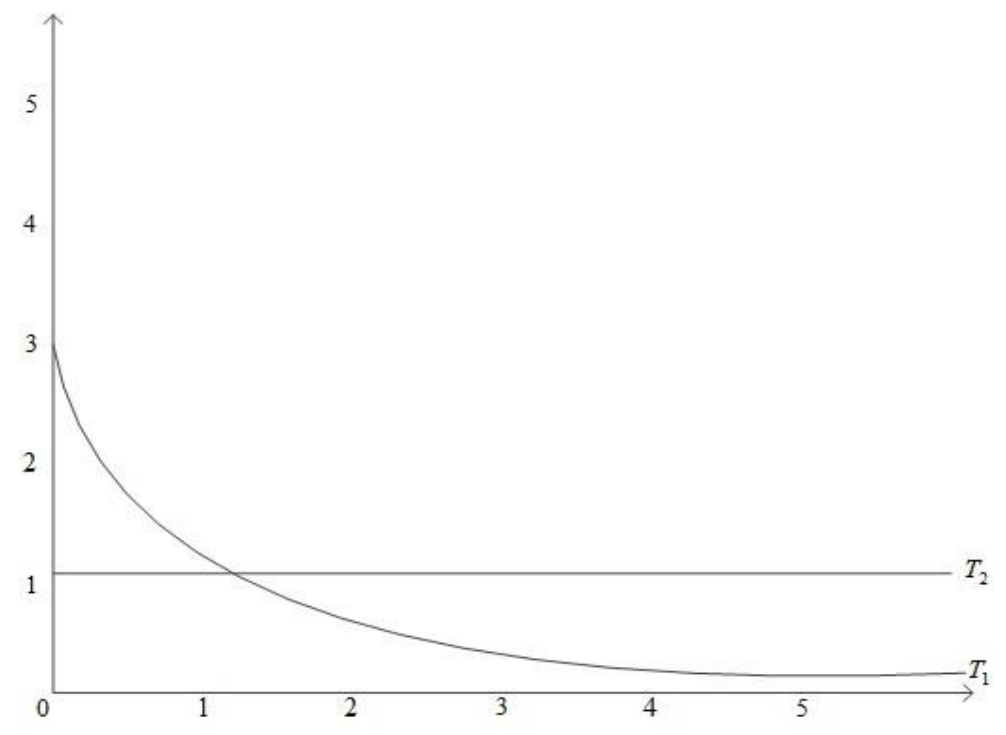

Figure 5. Comparison of the Profit of Manufacturer and the Retailer $(r=0)$ 
We can see that the slope of $T_{1}$ is very large at the beginning time and $T_{2}$ is almost equal to 1. In the above 3 pictures, we can see that except the common model of the orders of electronic channel being independent of retailer, sometimes the model delivery the orders of electronic channel to retailer can get more profit

\section{Conclusion}

This paper analyzes the electronic channels of manufacturer cooperate with retailer in a dual channel supply chain and compared with the familiar model that electronic channel is independent of retailer in literatures. When the manufacturer satisfying certain conditions in the traditional mode of the transfer coefficient of market demand to price, , manufacturers and retailers can get win-win results with choosing the way of collaborating with the electronic channels and retailers. Other than common model that electronic channel is independent of retailer, manufacturer collaborates with retailer in collaborate, excepting get more profit, the trust rank of manufacturer and retailer increase.

\section{Acknowledgment}

This paper belongs to the project of the "Twelveth Five-Year" Plan projects supported by National Science and Technology (No.2012BAH20F05)"research and application of Regional railway logistics information service platform", and is supported by youth foundation of Lanzhou Jiaotong University No.2012012)"research of Regional railway logistics Supply Chain Collaborative Service and its platform construction".

\section{References}

[1] W. Y. Chiang, D. Chhajed and J. D. Hess, "Direct marketing, indirect profits: A strategic analysis of dualchannel supply chain design", Management Science, vol. 49, no. 1, (2003), pp. 1-20.

[2] A. Dumrongsiri, F. Ming, A. Jain and K. A. Moinzadeh, "Supply chain model with direct and retail channels", European Journal of Operational Research, vol. 187, no. 3, (2008), pp. 691-718.

[3] A. Arya, B. Mittendorf and D. E. M. Sappingtou, "The bright side of supplier encroachment", Marketing Science, vol. 26, no. 5, (2007), pp. 651-659.

[4] Y. Liu and J. J. Zhang, "The benefits of personalized pricing in a channel”, Marketing Science, vol. 25, no. 1, (2006), pp. 97-105.

[5] M. Parlar, "Game-theoretic analysis of the substitutable product inventory problem with random demands", NavalResearchLogistics, vol. 35, no. 3, (1988), pp. 397-409.

[6] R. Anupindi, Y. Bassok and E. Zemel, "A general framework for the study of decentralized distribution systems”, Manufacturing and Service Operations Management, vol. 3, no. 4, (2001), pp. 349-368.

[7] A. Tsay and N. Agrawal, "Channel Conflict and Coordination: An Investigation of Supply Chain Design", New Jersey: Santa Clara University, (1999).

[8] D. Q. Yao and J. J. Liu, "Competitive pricing of mixed retail and e -tail distribution channels", Omega, vol. 33, no. 3, (2005), pp. 235-247.

[9] H. Kurata, D. Q. Yao and J. J. Liu, "Pricing polices under direct vs indirect channel competition and national vs store brand competition", European Journal of Operational Researeh, vol. 180, no. 1, (2007), pp. 262-281.

[10] R. Yan and Z. Pei, "Retail services and firm profit in a dual-channel market", Journal of Retailing and Consumer Services, vol. 16, no. 4, (2009), pp. 306-314.

[11] R. W. Seifert, U. W. Thonemann and W. H. Hausman, "Optimal procurement strategies for online spotmarket”, European Journal of Operational Research, vol. 152, no. 7, (2004), pp. 781-799.

[12] G. Cai, Z. G. Zhang and M. Zhang, "Game theoretical perspectives on dual -channel supply chain competition with price discounts and pricing schemes", International Journal of Production Economics, vol. 117, no. 1, (2009), pp. 80-96.

[13] Y. Ni-na1, H. Xiao-yuan and L. Bing, "Stackelberg Game Models of Supply Chain Dual-Channel Coordination in E-Markets", Chinese Journal of Management Science, vol. 15, no. 3, (2007), pp. 98-102.

[14] Q. Dao-gang and G. Ya-jun, "Coordination of Supply Chain with Hybrid Distribution Channels When Retailer's Demand Relies on Its Sales Effort", Chinese Journal of Management Science, vol. 16, no. 3, (2008), pp. 89-94. 
[15] X. Qing-hua and H. Pei-qing, "A Quantity Discount Model for Coordination of Internet-based Hybrid Channels", Systems Engineering-Theory \& Practice, vol. 27, no. 8, (2007), pp. 1-11.

[16] W. K. Chiang, "Product availability in competitive and cooperative dual-channel distribution with stock out based substitution", European Journal of Operational Research, vol. 200, no. 1, (2010), pp. 111-126.

[17] T. Boyaei, "Competitive stoking and coordination in amulti-channel distribution system", IIE Transactions, vol. 37, no. 5, (2005), pp. 407-427.

[18] J. Raju and Z. J. Zhang, "Channel coordination in the presence of a dominant retailer", Making Science, vol. 24, no. 2, (2005), pp. 254-262.

[19] D. Kuksov and A. Pazgal, "The Effects of costs and competition on slotting allowances", Making Science, vol. 26, no. 2, (2005), pp. 259-267.

[20] T. Geylani, A. J. Dukes and K. Srinivasan, "Strategic manufacturer response to a dominant retailer", Making Science, vol. 26, no. 2, (2007), pp. 164-178.

[21] S. Gupta and R. Loulou, "Process innovation product differentiation and channel structure: Strategic incentives in a duopoly", Making Science, vol. 17, no. 4, (1998), pp. 301-316.

[22] I. Giannoccaro and P. Pontrandolfo, "Supply chain coordination by revenue sharing contracts", InternationalJournal of Production Economics, vol. 89, no. 2, (2004), pp. 131-139.

[23] G.P. Cachon and M. A. Lariviere, "Supply chain coordination with revenue -sharing contracts: strengthsand limitations", Management Science, vol. 51, no. 1, (2005), pp. 30-44.

[24] W. Yong and P. Yong, "Revenue Sharing Contract of Supply Chain with Price-Sensitive End-Consumer Demand", Chinese Journal of Management Science, vol. 13, no. 6, (2005), pp. 29-33.

[25] C. Ju-hong, G. Fu-li and S. Cheng-dong, "On Supply Chain Revenue-Sharing Contract Design".

\section{Author}

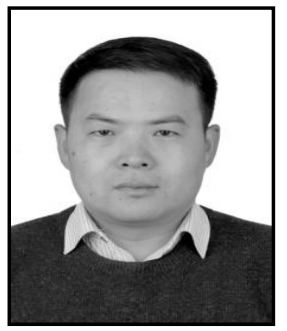

Jinping Qi, male, 1978-11, Zhucheng, Shandong, associate professor of Lanzhou Jiaotong University, master's degree in engineering, Ph. D. student. Research direction: logistics equipment informationization, the whole logistics service chain coordination. 